\title{
Tingkat Keberhasilan Dakriosistorinostomi Eksternal di RS Saiful Anwar Malang
}

\section{The Success Rate of External Dacryocystorhinostomi at Saiful Anwar Hospital Malang}

\author{
RM Fattahillah Malik, Debby Shintiya D \\ Laboratorium IImu Kesehatan Mata RSU Dr. Saiful Anwar Malang
}

\begin{abstract}
ABSTRAK
Dakriosistorinostomi eksterna masih menjadi pilihan tindakan terhadap keluhan epifora karena stenosis atau obstruksi duktus nasolakrimalis dengan tingkat keberhasilan yang dilaporkan tinggi. Penelitian dilakukan untuk mengetahui tingkat keberhasilan dakriosistorinostomi dengan intubasi silikon yang telah dilakukan di RS Saiful Anwar Malang selama tahun 2006 - 2012 dengan mengevaluasi data rekam medik. Enam belas pasien termasuk dalam kriteria inklusi penelitian, jumlah pasien perempuan 10 orang (62,5\%) sedangkan laki-laki berjumlah 6 orang (37,5\%). Kelompok usia terbanyak yang menjalani operasi adalah 21-30 tahun berjumlah 4 orang (25\%), patologi terbanyak adalah dakriosistitis kronis berjumlah 7 pasien (43,8\%). Hasil dari pemeriksaan anel tes didapatkan komplet obstruksi pada 14 pasien (87,5\%), dilakukan operasi terbanyak pada mata kiri dengan $75 \%$. Silikon intubasi dipasang pada semua pasien dengan lama intubasi terpasang terbanyak selama 6 bulan atau lebih sebesar $56,2 \%$. Evaluasi keluhan mata berair pasca operasi dan anel tes pasca operasi didapatkansebesar 87,5\% tanpa keluhan subjektif lagi dengan pada anel tes tidak didapatkan obstruksi ataupun regurgitasi baik total maupun parsial. Tingkat keberhasilan dakriosistorinostomi eksterna dengan intubasi silikon di RS Saiful Anwar cukup baik sehingga dapat menjadi pilihan utama manajemen obstruksi duktus nasolakrimalis.
\end{abstract}

Kata Kunci: Dakriosistorinostomi eksterna, intubasi silikon, obstruksi duktus nasolakrimal

\section{ABSTRACT}

External dacryocystorhinostomy (DCR) is the standard treatment for nasolacrimal duct obstruction, with high success rates reported. The procedure is effective with low cost compared to other nasolacrimal duct surgery. This study aimed to evaluate the successful rate of external dacryocystorhinostomi with silikone intubation at Saiful Anwar Hospital Malang in 6 years (2006-2012) based on patient medical record data. Sixteen patients included in this study, with 62,5\% female and most of them are at 21-30 years old (25\%). Chronic dacryocystitis is the main indication for surgery (43,8\%) and most the procedure is performed on the left eye (75\%). There are 14 patients with complete obstruction from anel test examination. Silicone intubasion were implanted in all patient and 56,2\% of it were implanted for 6 months. After silicone intubation released, $87,5 \%$ patients have reported no subjective complaints with negative obstruction and regurgitation based on anel test. Successful rate of external dacryocystorhinostomy with silicone intubation at Saiful Anwar hospital is comparable to previous research suggested that this method remain the best option for nasolacrimal duct obstruction management.

Keywords: External dacryocystorhinostomy, nasolacrimal duct obstruction, silicone tube intubation

Jurnal Kedokteran Brawijaya, Vol. 28, No. 1, Februari 2014; Korespondensi: RM Fattahilah Malik. Laboratorium Ilmu Kesehatan Mata Rumah Sakit Dr. Saiful Anwar Malang, Jl. Jaksa Agung Suprapto No. 2 Malang Tel. (0341) 341945 Email: patah610@yahoo.com 


\section{PENDAHULUAN}

Dakriosistorinostomi eksterna masih menjadi pilihan tindakan terhadap keluhan epifora karena stenosis atau obstruksi duktus nasolakrimalis. Tingkat keberhasilan operasi mencapai $92 \%$ pada kelainan yang tanpa disertai adanya penyakit pada kanalikuli (1). Peter et al melaporkan keberhasilan mencapai 90,2\% masih lebih baik bila dibandingkan dengan tindakan endonasal non laser dariosistorinostomi (2).

Berbagai laporan tindakan dakriosistorinostomi eksterna dengan intubasi silikon memberikan hasil lebih baik dibandingkan dakriosistorinostomi endonasal. Saroj et al melaporkan tingkat keberhasilan eksterna dakriosistorinostomi mencapai 95\% lebih baik dibandingkan dakriosistorinostomi endonasal yang mencapai $90 \%$ (3). Guy et al melaporkan berbeda dengan Gupta dimana tingkat keberhasilan yang lebih rendah pada dakriosistorinostomi eksterna dibandingkan pada dakriosistorinostomi endonasal, pada dakriosistorinostomi eksterna hanya $77 \%$ sedangkan pada dakriosistorinostomi endonasal mencapai 84\% (4).

Keberhasilan dakriosistorinostomi eksterna ditunjang oleh identifikasi anatomis yang baik dari saccus lakrimalis maupun lapisan mukosa dan teknik yang dipakai saat operasi. Penjahitan flap posterior pada saat operasi memberikan tingkat keberhasilan yang lebih baik dibandingkan tindakan eksisi flap posterior. Komplikasi yang dapat terjadi pada tindakan eksterna dacriositorinostomi diantaranya perdarahan pada daerah hidung pasca operasi, piogenik granuloma, sindroma sump, kebocoran cairan cerebrospinal, kerusakan jaringan orbita, eversi pungtum, dan perdarahan yang tidak terkontrol (5). Tujuan penelitian ini adalah mengetahui tingkat keberhasilan dakriosistorinostomi dengan intubasi silikon yang telah dilakukan di RSU Dr. Saiful Anwar Malang selama tahun 2006 hingga 2012.

\section{METODE}

Penelitian deksriptif retrospekstif dilakukan dengan mengambil data dari rekam medis RSU Dr. Saiful Anwar pada semua pasien yang menjalani operasi dakriosistorhinostomi di bagian mata RSSA antara tahun 2006 hingga 2012. Data yang diamati meliputi karakteristik demografi pasien, gambaran kondisi patologis, dan efektifitas terapi yang diukur dengan perbaikan keluhan subjektif dan hasil tes anal tiga bulan sesudah tindakan. Data dianalisa secara deskriptif menggunakan SPSS 16 for Windows.

\section{HASIL}

Jumlah seluruh pasien yang telah dioperasi sejak tahun 2006 hingga 2012 berjumlah 24 orang, 16 orang termasuk dalam kriteria inklusi penelitian sisanya sebanyak 8 orang tidak termasuk kriteria inklusi karena tidak lagi kontrol pasca silikon tube dilepaskan. Jumlah pasien laki-laki sebanyak 6 orang $(37,5 \%)$ dan 10 orang $(62,5 \%)$ adalah perempuan. Kelompok umur penderita terbanyak yang menjalani dakriosistorinostomi eksterna adalah kelompok usia 21-30 tahun sebanyak 25\% (4 pasien). Kelompok usia 0-10 tahun, 31-40 tahun dan kelompok usia lebih dari 50 th jumlahnya sama masing-masing kelompok umur berjumlah 2 pasien (12,5\%). Pasien termuda yang menjalani operasi berusia 4 tahun dengan kelainan yang mendasari adalah kongenital dan pasien tertua berusia 66 tahun yang dilakukan operasi karena dakriosistitis kronis

Kelainan yang mendasari dilakukannya tindakan dakriosistorinostomi eksterna pada pasien diantaranya dakriosistitis kronis, obstruksi duktus nasolakrimal pasca trauma, obstruksi duktus nasolakrimal congenital, dan kista saccus lakrimalis. Dakriosistitis kronis merupakan patologi terbanyak yaitu berjumlah 7 pasien $(43,8 \%)$, obstruksi duktus nasolakrimal karena kelainan kongenital dan sekunder karena trauma berjumlah 4 pasien (25\%) dan 1 pasien karena adanya kista saccus lakrimalis.

Pada saat dilakukan anel tes pre operasi didapatkan regurgitasi pada pungtum superior. Hal ini menunjukkan adanya obstruksi komplet pada duktus nasolakrimalis. Pada semua pasien yang akan dioperasi dakriosistorinostomi eksterna didapatkan blokade komplit pada hampir semua pasien $(87,5 \%)$ sedangkan pada 2 pasien $(12,5 \%)$ didapatkan parsial regurgitasi yang menandakan parsial obstruksi dari duktus nasolakrimal.

Distribusi lateralisasi pada mata kiri $(56,25 \%)$ lebih sering dibandingkan mata kanan (18,75\%) sedangkan kelainan pada kedua mata didapatkan pada 4 pasien (25\%). Dari kelainan tersebut tindakan operasi dakriosistorinostomi eksterna dilakukan paling banyak pada mata kiri sebanyak 12 operasi (75 \%) dan pada mata kanan berjumlah 4 operasi $(25 \%)$.

Tabel 1. Gambaran karakteristik umum dan klinis pasien dengan operasi dakriosistorinostomi eksterna

\begin{tabular}{|c|c|c|}
\hline \multirow{2}{*}{ Karakteristik } & \multicolumn{2}{|c|}{ Frequensi } \\
\hline & Prosentase & Jumlah \\
\hline \multicolumn{3}{|l|}{ Jenis Kelamin: } \\
\hline Laki-laki & $37,5 \%$ & 6 \\
\hline Perempuan & $62,5 \%$ & 10 \\
\hline \multicolumn{3}{|l|}{ Kelompok Usia: } \\
\hline $0-10$ & $12,5 \%$ & 2 \\
\hline $11-20$ & $18,75 \%$ & 3 \\
\hline $21-30$ & $25 \%$ & 4 \\
\hline $31-40$ & $12,5 \%$ & 2 \\
\hline $41-50$ & $18,75 \%$ & 3 \\
\hline$>50$ & $12,5 \%$ & 2 \\
\hline \multicolumn{3}{|l|}{ Tindakan Operasi: } \\
\hline Obstruksi DNL Ec Dacriosistitis & $43,75 \%$ & 7 \\
\hline Obstruksi Pasca Trauma & $25 \%$ & 4 \\
\hline Obstruksi DNL Congenital & $25 \%$ & 4 \\
\hline Kista Saccus Lacrimlis & $6,25 \%$ & 1 \\
\hline \multicolumn{3}{|l|}{ Tes Anel sebelum Operasi: } \\
\hline Regurgitasi Parsial & $87,5 \%$ & 14 \\
\hline Total Regurgitasi & $12,5 \% \%$ & 2 \\
\hline \multicolumn{3}{|l|}{ Distribusi Lateralisasi: } \\
\hline Mata kanan & $18,75 \%$ & 3 \\
\hline Mata kiri & $56,25 \%$ & 9 \\
\hline Kedua mata & $25 \%$ & 4 \\
\hline
\end{tabular}

Semua pasien yang menjalani operasi bedah dakriosistorinostomi eksterna dilakukan intubasi silikon dan pengambilan atau lama terpasangnya intubasi silikon dibagi dalam dua kelompok yaitu kelompok I dengan lama intubasi silikon kurang dari 6 bulan dan kelompok kedua dengan lama terpasangnya intubasi silikon 6 bulan atau lebih. Pada 7 pasien $(43,8 \%)$ intubasi siliko dipasang kurang dari 6 bulan dan 9 pasien (56,2\%) terpasang 6 bulan atau lebih. Intubasi silikon paling cepat di lepas 
setelah 1 bulan dan paling lama terpasang selama 8 bulan.

Tingkat keberhasilan operasi dinilai dari keluhan mata berair pasca operasi dan tes anel pasca operasi setelah setidaknya 3 bulan pasien kontrol. Dari distribusi keluhan mata berair didapatkan $87,5 \%$ atau 14 pasien tidak lagi mengeluhkan mata selalu berair dan 2 pasien (12,5\%) masih didapatkan keluhan mata selalu berair. Saat dilakukan anel tes pada 87,5 \% hasilnya adalah paten dan tidak ada regurgitasi baik pada pungtum inferior maupun pungtum superior, sedangkan pada 2 pasien (12,57\%) didapatkan parsial regurgitasi, pasien yang mengalami parsial regurgitasi merupakan pasien yang masih mengeluhkan mata yang sering berair. Hasil ini menunjukkan tingkat keberhasilan dakriosistorinostomi eksterna sebesar $87,5 \%$.

\section{DISKUSI}

Penelitian deskriptif ini dilakukan untuk mengetahui tingkat keberhasilan operasi dakriosistorhinostomi eksterna di RSU Dr. Saiful Anwar Malang yang telah dilakukan pada periode 2006-2012. Data diambil dari rekam medis pasien, jumlah seluruh operasi yang dilakukan sejak 2006 hingga 2012 berjumlah 24 operasi. Jumlah pasien yang diinklusi pada penelitian ini 16 orang dimana jumlah terbanyak adalah perempuan yaitu $62,5 \%$, sedangkan jumlah pasien pria yang sudah menjalani operasi 6 orang $(37,5 \%)$. Faisal et al menyatakan pada pasien yang dilakukan dacriosistorhinostomi eksterna didapatkan 50 dari 70 pasien adalah perempuan (71,4\%) dan prosentase laki-laki $28,5 \%$. Sesuai dengan penelitian yang dilakukan Saroj et al pasien laki-laki jumlahnya lebih sedikit hanya 5 dari 20 pasien (25\%) dibandingkan dengan pasien perempuan (75\%) (5). Sementara Guy et al demografi jenis kelamin yang menjalani dakriosistorhinostomi eksterna untuk laki-laki 34\% dan perempuan 66\% (4). Secara teori penelitian di RSU Dr. Saiful Anwar ini tidak berbeda dengan penelitian sebelumnya dimana predileksi perempuan lebih besar dibanding laki-laki.

Salah satu faktor yang menyebabkan kasus pada perempuan lebih besar diantaranya karena diameter kanal dari tulang nasolakrimal pada perempuan lebih kecil dibandingkan pada laki-laki. Menurut Jansen, perempuan memiliki diameter minimum yang lebih kecil dengan rerata $0,35 \mathrm{~mm}$, yang mengakibatkan terjadi stasis dan infeksi dari kavum nasi, selain itu posisi canal tulang nasolakrimal ini lebih flat dibandingkan pada laki-laki (6). Shigeta et al menemukan bahwa kaliber dari tulang duktus nasolakrimal dan sudut yang dibentuk antara tulang duktus lakrimal dan basis nasal meningkat seiring usia yang akibatnya akan lebih memendekkan canal nasolakrimal dan adanya sudut yang terbentuk akan menyebabkan predisposisi terjadinya inflamasi kronis dari sistem drainase lakrimal (7). Hubungan yang erat jalur nasolakrimal dengan dinding lateral kavum nasi dan sinus paranasal menyebabkan rentannya proses inflamasi dan obstruksi nasolakrimal yang terjadi karena berbagai patologi dari kavum nasi dan sinus paranasal, dan hampir $50 \%$ inflamasi sino-nasal berkaitan dengan terjadinya obstruksi duktus nasolakrimal. Infeksi akut dari kavum nasi, infeksi kronis dan berulang yang terjadi di sinus paranasal diduga menyebabkan perluasan infeksi melalui duktus nasolakrimal diikuti inflamasi mucosa, edema, pembentukan jaringan sikatrik dan berujung pada stenosis (8).
Dari data penelitian didapatkan kelompok umur yang menjalani operasi terbanyak dari usia 21-30 tahun (25\%) diikuti kelompok usia 41-50 th dan 11-20 tahun. Berbeda dengan Saroj yang menemukan kelompok usia yang terbanyak menjalani operasi adalah kelompok usia 41-50 tahun (35\%) (3). Guy et al menyatakan rata-rata usia pasien yang telah menjalani operasi dakriosistorinostomi eksterna adalah $66 \pm 19$ th (4). Salahuddin menyebutkan kelainan ini sering didapatkan pada kelompok usia 20-30 tahun dan kelompok usia 50-60 tahun. Diduga pada usia ini penderita masih produktif dalam status pekerjaan, dengan resiko terpajan berbagai agen patogen lebih besar. Bila dilihat dari status pekerjaan mereka yang paling banyak menderita adalah buruh, diikuti ibu rumah tangga, satpam dan siswa, kelompok sosio ekonomi yang terkena dakriosistitis kronis adalah orang dengan sosioekonomi rendah dan menengah, hampir tidak didapatkan pada orang dengan sosio ekonomi tinggi yang diduga karena pada sosio ekonomi tinggi lebih bisa menjaga kebersihan dari mata (9). Obstruksi duktus nasolakrimal banyak pada orang tua di usia 50-60 tahun karena pada usia tua terjadi perubahan fossa nasolakrimal bawah dan duktus nasolakrimal bagian tengah yang cenderung lebih kecil dimensinya, perubahan anteroposterior dari tulang nasolakrimal ini seiring (coincidence) dengan perubahan osteoporosis pada usia tersebut. Selain itu perubahan hormonal diduga menyebabkan de-epitelisasi yang dapat menyebabkan semakin sempitnya fossa lakrimalis karena adanya penumpukan debris di lokasi tersebut (10).

Pada penelitian ini didapatkan berbagai patologi sebagai dasar dilakukannya tindakan bedah dakriosistorinostomi eksterna diantaranya obstruksi duktus nasolakrimalis yang disebabkan karena dakriosistitis, obstruksi duktus nasolakrimal sekunder pasca trauma, karena kelainan kongenital dan kista saccus lakrimalis. Menurut Kim et al 44 operasi DCR eksterna dari 57 operasi disebabkan karena adanya obstruksi duktus nasolakrimalis primer (PANDO), faktor kelainan kongenital hanya 3 operasi dan obstruksi yang didapat karena adanya keratokonjungtivitis epidemik pada 2 pasien.

Tes anel pada pemeriksaan pasien preoperasi pada penelitian ini menunjukkan obstruksi total didapatkan pada $87,5 \%$ pasien, hanya pada 2 pasien $(12,5 \%)$ terdapat regurgitasi parsial. Pada pemeriksaan ini tidak ditunjang dengan pemeriksaan dakriosistografi sehingga detail kelainan anatomis tidak bisa dipastikan. Kelainan atau komplikasi pre operasi dan pasca operasi dapat mengganggu keberhasilan operasi. Dakriosistografi dapat menilai letak kelainan anatomis pada level tertentu baik di saccus lakrimalis, kanaliculi maupun kanaliculi kommunis. Dakriositografi juga dapat menilai keberhasilan pasca operasi dan mengetahui kelainan anatomis pasca operasi (11).

Tindakan bedah dakriosistorinostomi eksterna semuanya di RSU Dr. Saiful Anwar semuanya menggunakan intubasi silikon dengan lama intubasi silikonsilikon terpasang yang bervariasi. Tindakan bedah dengan intubasi silikon lebih diterima dibandingkan dengan tindakan dakriosistorinostomi eksterna murni tanpa intubasi silikon, karena hasil operasi yang lebih baik (12). Charalampidou menyatakan bahwa resolusi sempurna pada intubasi silikonsilikon yang terpasang selama 4 bulan lebih banyak bila dibandingkan pada intubasi silikon yang terpasang 2 bulan dan 2 hingga 4 bulan (13). Matthew menyimpulkan bahwa lama intubasi silikon tidak mempengaruhi keberhasilan operasi dakriosistorinostomi eksterna dan merekomendasikan untuk lama pemasangan 
intubasi silikon adalah 2 bulan, namun hal ini tidak berlaku bila terdapat laserasi dan kelainan kongenital (14). Lama intubasi silikon yang terpasang pada pasien operasi di RSU Dr. Saiful Anwar sudah sesuai dengan berbagai penelitian yang telah dilakukan yang menunjukkan dua pasien terjadi parsial resolusi pada pemasangan intubasi silikon yang terpasang 6 bulan, sementara pada semua pasien yang terpasang intubasi silikon kurang dari 6 bulan terjadi resolusi sempurna.

Dakriosistorinostomi eksterna dapat dilakukan pada obstruksi duktus nasolakrimal pada anak-anak dengan tingkat keberhasilan yang sama seperti pada dewasa, namun tindakan pada anak sebaiknya dilakukan penjahitan pada flap anterior saccus lakrimalis dan mukosa nasi. Sedangkan keberhasilan untuk intubasi silikon pada kasus obstruksi duktus nasolakrimalis congenital masih memerlukan studi lebih lanjut $(15,16)$. Pada penelitian ini tingkat keberhasilan untuk obstruksi duktus nasolakrimalis pada anak dicapai $100 \%$, semua pasien dipasang silikon tube, namun tidak terdapat informasi detail tehnik yang digunakan, penjahitan pada flap anterior dan mukosa nasi tidak dijelaskan.

Secara umum keberhasilan tindakan operasi dakriosistorinostomi eksterna di RS Saiful Anwar dicapai

\section{DAFTAR PUSTAKA}

1. Boboridis KG, Bunce C, and Rose GE. Outcome of External Dacryocystorhinostomy Combined with Membranectomy of a Distal Canalicular Obstruction. American Journal of Ophthalmology. 2005; 139(6): 1051-1055.

2. Dolman PJ. Comparison of External Dacryocystorhinostomy with Nonlaser Endonasal Dacryocystorhinostomy. Ophthalmology. 2003; 110(1): 78-84.

3. Gupta S and Goyal R. Conventional Dacryocystorhinostomy Versus Endonasal Dacryocystorhinostomy a Comparative Study. Indian Journal of Otolaryngology and Head \& Neck Surgery. 2010; 62(3): 296-298.

4. Ben Simon GJ, Joseph J, Lee S, Schwarcz RM, McCann JD, and Goldberg RA. External versus Endoscopic Dacryocystorhinostomy for Acquired Nasolacrimal Duct Obstruction in a Tertiary Referral Center. Ophthalmology. 2005; 112(8) :1463-1468.

5. Khan FA, Yaqub MA, and Fayyaz M. The Importance of Excising or Suturing the Posterior Mucosal Flaps in External Dacryocystorhinostomy. Pakistan Journal of Ophthalmology. 2010; 26(2):69-73

6. Janssen AG, Mansour K, Bos JJ, and Castelijns JA. Diameter of the Bony Lacrimal Canal: Normal Values and Values Related to Nasolacrimal Duct Obstruction: Assessment with CT. American Journal of Neuroradiology. 2001; 22(5): 845-850.

7. Shigeta K, Takegoshi $\mathrm{H}$, and Kikuchi S. Sex and Age Differences in the Bony Nasolacrimal Canal: An Anatomical Study. JAMA Ophthalmology. 2007; 125(12): 1677-1681.

8. Önerci M. Dacryocystorhinostomy. Diagnosis and Treatment of Nasolacrimal Canal Obstructions. Rhinology. 2002; 40(2): 49-65.

9. MAAhmed. A Clinical Study of Chronic Dacryocystitits. Journal of the Indian Medical Association.2006;
$87,5 \%$, sedangkan sisanya $(12,5 \%)$ patensi duktus nasolakrimal masih belum sempurna. Evaluasi keberhasilan ini meliputi keluhan subjektif berupa tearing dan tes anel pasca intubasi silikon dilepaskan. Adanya keluhan tearing yang menetap dan pada anel tes masih didapatkan adanya regurgitasi parsial dapat dinyatakan tindakan bedah berhasil sebagian (partial success) sesuai dengan kriteria dari Guy (4).

Bila dibandingkan dengan penelitian sebelumnya maka tingkat keberhasilan operasi dakriosistorinostomi eksterna di RSU Dr. Saiful Anwar sedikit dibawah penelitian di tempat lain. Dolman di Vancouver menyatakan tingkat keberhasilan dakriosistorinostomi eksterna dicapai pada 90\%, Aziz menemukan keberhasilan dakriosistorinostomi eksterna mencapai 97,1\% (2,5). Tsirbas et al melakukan studi di Adelaide dengan tingkat keberhasilan mencapai 96 persen (17), dan Mirza et al menyimpulkan hasil yang dicapai sebesar $94 \%$ (18). Begitu pula dengan penelitian yang dilakukan Baig mencapai $87 \%$. Beberapa kekurangan yang terdapat pada penelitian ini yaitu minimnya data pendukung yang dapat digunakan sebagai data penunjang. Beberapa pasien tidak dilakukan dakriosistografi sehingga tidak dapat diketahui kelainan anatomis yang didapat.

\section{6(5): 190-198}

10. Babar TF, Masud MZ, Saeed N, and Khan MD. An Analysis of Patients with Chronic Dacryocystitits. Journal of Postgraduate Medical Institute. 2003; 18(3): 424-432.

11. Manfrè L, de Maria $M$, Todaro E, Mangiameli $A$, Ponte F, and Lagalla R. MR Dacryocystography: Comparison with Dacryocystography and CT Dacryocystography. American Journal of Neuroradiology. 2000; 21(6): 1145-1150.

12. Lone IA, Wahab A, Ahmad SS, and Untoo RA. Repeat DCR with Silikone Tube Intubation: A Prospective Study. JK Science. 2004; 6(2): 70-72.

13. Charalampidou $\mathrm{S}$ and Fulcher T. Does the Timing of Silikone Tube Removal Following External Dacryocystorhinostomy Affect Patients' Symptoms? Orbit. 2009; 28(2-3): 115-119.

14. Vicinanzo MG, McGwin G, Boyle M, and Long JA. The Consequence of Premature Silikone Stent Loss after External Dacryocystorhinostomy. Ophthalmology. 2008; 115(7): 1241-1244.

15. Maheswari R. External Dacryosistorhynostomy for Paediatric Nasolacrimal Duct Obstruction. Asian Journal Ophthalmology. 2006; 8: 242-244.

16. Khan N, Khan MN, Jan S, and Mohammad S. Congenital Nasolacrimal Duct Obstruction: Presentation and Mangement. Pakistan Journal of Ophthalmology. 2006; 22(2): 74-79.

17. Tsirbas A, Davis G, and Wormald PJ. Mechanical Endonasal Dacryocystorhinostomy versus External Dacryocystorhinostomy. Ophthalmic Plastic and Reconstructive Surgery. 2004; 20(1): 50-56.

18. Mirza S, Al-Barmani A, and Douglas SA. A Retrospective Comparison of Endonasal KTP Laser Dacryocystorhinostomy versus External DacryocystoRhinostomy. Clinical Otolaryngology. 2002; 27: 347-351. 